\title{
"Traer cortita a la mujer". Una creencia sobre las relaciones de género en jóvenes de Guadalajara
}

\author{
Juan Carlos Ramírez Rodríguez* \\ UNIVERSIDAD DE GUADALAJARA
}

En este artículo se describe e interpreta la creencia "traer cortita a la mujer". Es una modalidad de la dominación masculina y una expresión de la violencia simbólica enmarcada en las relaciones de género. No existe una concepción homogénea sobre la misma como se constata en el estudio llevado a cabo en jóvenes. Se registran posiciones a favor y en contra, esto es, se puede considerar como una expresión de machismo, de control, pero también puede verse como una necesidad, como una forma pertinente de relación. También se observan a través de los testimonios, expresiones de ambivalencia e incluso de indiferencia ante esta creencia. "Traer cortita a la mujer" permite percatarse de la importancia de las creencias como elementos constituyentes de las relaciones de género y evidenciar sus continuidades, adaptaciones y transformaciones. La comprensión de las creencias es indispensable para alentar modificaciones tendientes a la igualdad, la solidaridad, el diálogo y la negociación entre los géneros. Participaron jóvenes (mujeres y hombres), entre 15 y 24 años, estudiantes de preparatoria y licenciatura residentes en la zona metropolitana de Guadalajara. Se utilizó la técnica de grupos focales.

(Género, creencias, jóvenes, violencia de género, masculinidad, dominación masculina)

\footnotetext{
l objetivo de este artículo es describir e interpretar una creencia que prevalece en las y los jóvenes para referir una manera específica de vínculo entre una mujer y un hombre: "traérsela cortita". Se aplica a la manera como el hombre determina la relación

* jucarlosra@gmail.com Agradezco al Comité Dictaminador de la Revista y a Griselda Uribe Vázquez por los comentarios a una versión previa del artículo.
} 
afectiva con la mujer. El artículo está divido en cuatro secciones. En la primera se presenta una breve perspectiva sobre la violencia de género y se puntualizan algunos aspectos sobre las creencias. La segunda contiene la metodología. En la tercera se muestra la concepción que mujeres y hombres sostienen sobre "traer cortita a la mujer". La última se dedica a presentar algunas consideraciones a manera de conclusión.

\section{VIOLENCIA DE GÉNERO Y CREENCIAS}

Por violencia de género (vG) se puede entender la que ejercen los hombres y las mujeres entre sí. También aquella entre hombres o entre mujeres. Aquí se acota para entenderla como

una práctica social, mediada por relaciones entre los géneros que se constituyen y materializan en formas de ejercicio de poder, siempre en contextos de asimetría que atentan contra la integridad de las mujeres y favorecen su subordinación y control por parte de los varones. Sus expresiones pueden identificarse como conductas (acciones u omisiones) sean de carácter real o simbólico (Ramírez Rodríguez 2006, 315).

Es un fenómeno universal con implicaciones sociales, culturales, políticas, económicas, ideológicas, legales, sanitarias. Sus efectos han sido evidenciados en los niveles institucional, comunitario, familiar e individual. Las acciones para enfrentarlo han estado encaminadas a las modificaciones de marcos legales, al diseño e instrumentación de programas de atención, sensibilización y prevención (Naciones Unidas 1989; OMs 2003; Naciones Unidas 2006).

En México, la prevalencia de la vg es elevada (Ramírez Rodríguez y Uribe Vázquez 1993; Ramírez Rodríguez y Vargas Becerra 1998; INEGi 2004; Olais, del Río et al. 2004; INEGI 2008; Instituto Mexicano de la Juventud 2008; Instituto Nacional de Salud Pública 2008), mostrando sus efectos deletéreos en las mujeres (Ramírez Rodríguez 2006). También se han implantado diversos programas y acciones para enfrentarla (Valdez Santiago y Juárez 1998; Valdez Santiago 2004; Valdez Santiago, Arenas Monreal et al. 2004; Camara de Diputados del Honorable Congreso de la Unión 2009) y esta- 
blecido observatorios en distintos estados del país para monitorear su incidencia y las maneras de resolverla desde distintas instancias gubernamentales, privadas y de la sociedad civil (Red Nacional de Observatorios de Violencia Social y de Género 2010). Todas estas acciones han ido develando la complejidad de la vG. Otra de sus facetas es la serie de creencias sobre la propia vG que se enmarcan a su vez en las establecidas sobre las relaciones de género. Estas últimas implican la significación y práctica de toda relación social en la que participan sujetos sexuados de acuerdo al contexto sociocultural en un momento particular (Scott 1997; Connell 1995).

Las creencias sobre las relaciones de género y la VG en particular son un campo en disputa constante, sugiere la existencia de universos simbólicos que subyacen a los mismos. Lo que está en juego son formas de ejercicio de poder, de representación social. Unas tendientes a mantener contextos de desigualdad, dominación, privilegio y otras que impulsan relaciones de igualdad, de respeto por las diferencias, que valoran las relaciones democráticas en las que el diálogo tiene un papel central.

Las creencias sobre la VG que con más frecuencia se refieren aluden a la causalidad centradas en el individuo (enfermedad mental, uso de drogas, inclinación natural de la mujer a ser maltratada) (Ramírez Rodríguez 1999; Welzer-Lang 2007). Otros tratan de identificar la vinculación con los contextos socioculturales, por ejemplo, Steinmetz y Haj-Yahhia al estudiar las creencias sobre la violencia de género entre judíos ortodoxos identificaron un grupo mayoritario que rechazaba esta forma de abuso, mientras otros la avalaban y justificaban en función de una ideología patriarcal (Steinmetz y HajYahia 2006). A las creencias sobre la VG subyacen aquellas que refieren las relaciones entre los géneros en un sentido más amplio (Ramírez Rodríguez, López López et al. 2009). Modificar las relaciones entre los géneros es un componente indispensable para prevenir la VG. Las propuestas de prevención, que se encuentran en una etapa primaria de desarrollo tienen un efecto cognitivo positivo, pero las actitudes y las prácticas de la VG parecen no modificarse de manera sustantiva en la población joven, en especial en el largo plazo (Foshee 1996; Foshee, Bauman et al. 2004). Las creencias sobre las relaciones 
entre los géneros y la vG son elementos claves para comprender lo que Bourdieu ha denominado como la violencia simbólica (Bourdieu 1991; Bourdieu y Wacquant 1995), que sostiene diversas formas de dominación, entre ellas la dominación masculina. Así afirma que "es completamente ilusorio creer que la violencia simbólica puede vencerse exclusivamente con las armas de la conciencia de la voluntad, la verdad es que los efectos y las condiciones de su eficacia están duraderamente inscritos en lo más íntimo de los cuerpos bajo forma de disposiciones" (Bourdieu 2000, 55), de ahí la complejidad y dificultad para modificar las prácticas de relación de dominación, porque la dominación está instituida no en el campo de lo cognitivo de manera exclusiva, sino en los procesos de percepción del mundo, en las creencias, en las estructuras que moldean la dominación.

Bajo este supuesto, las creencias tendrían un papel central en la reproducción de la VG, de ahí que importe la manera como se conciben y (re)crean. Las creencias pueden entenderse como irracionales, opuestas al conocimiento racional (Good 2003), con una serie de características como: asumirse sin comprobación lógica o filosófica sino por conformidad; no se cuestionan pero si se refuerzan repitiendo una argumentación aprendida de manera mecánica, lo que genera certidumbre psicológica (Arispe 1989). También se han concebido las creencias como "ideas radicales", que a diferencia de una ocurrencia, que es algo que se piensa, las creencias "constituyen el continente de nuestra vida [...] no son ideas que tenemos, sino ideas que somos" (Ortega y Gasset 1968 (1940, 24-25). Este último planteo permite asociar a las creencias como parte de la subjetividad del sujeto, a partir de la cual se hace una lectura del mundo y se desarrolla una práctica social de la que parece difícil tener conciencia y transformarse. Villoro por su parte es más preciso al considerar la creencia como "un estado disposicional adquirido, que causa un conjunto coherente de respuestas y que está determinado por un objeto o situación objetiva aprehendidos" (Villoro 1989, 71). Tres son los componentes de esta definición: a) La disposición del sujeto, que no es natural o esencial al mismo, sino que se adquiere. El contexto sociocultural determina la construcción de esta disposición; b) las respuestas a que da lugar tal disposición. La relación no es de causa-efecto, sino 
parecería una suerte de probabilidad, ya que son un conjunto de respuestas que tienen como característica ser coherentes. Tienen un sentido, siempre con un rango de variabilidad; c) la disposición está determinada por un objeto o situación aprehendidos. Las creencias tienen un referente concreto, en otras palabras, son específicas, de manera que se sortea cualquier posible ambigüedad.

La creencia se adopta, se aprehende, no es un elemento espontáneo. Siempre tiene un antecedente biográfico del que puede o no tenerse memoria, que le da origen a la creencia que tiene el sujeto. También existen motivos para creer porque solventa necesidades, cumple deseos, por tanto tiene una función específica para el sujeto. Además, se fundamenta en operaciones lógicas (se racionaliza) cuando se cuestiona, lo que permite al sujeto asumir como verdadera la creencia (Villoro 1989).

Las relaciones entre mujeres y hombres jóvenes, como cualquier otra forma de relación social, están sustentadas en una serie de creencias convencionales. Su expresión no es unívoca, el significado de las creencias cambia. En ocasiones son matices, en otras, los significados son contrapuestos. Es pertinente identificar las variantes que se expresan sobre las creencias y observar con atención el vínculo con las relaciones familiares, la convivencia con sus pares, la exposición a información que proviene de los medios masivos de comunicación y la escuela, entre otros. La acumulación de experiencias propias o la observación y escucha atenta de las que les ocurren a personas cercanas son fuente constante de reafirmación o reformulación de creencias.

Así, por ejemplo, entre mujeres brasileñas jóvenes (18-21 y 3039 años), de sectores de ingresos bajos y medios, se exploraron las creencias en torno a la primera experiencia sexual y se encontraron las siguientes: que los hombres necesitan tener sexo porque su deseo es irrefrenable; que las mujeres serán abandonadas si no acceden a tener sexo con sus parejas, aun cuando la pareja explicite su acuerdo en esperar a que ella lo decida, porque el hombre no puede ir contra su naturaleza; que cuando la mujer tiene su primera relación sexual debe actuar de manera pasiva, de otra manera el hombre no la creería virgen; que siempre debe resistirse al avance sexual de su pareja, 
aunque ella lo desee (Moore 2006). La sexualidad y el cortejo se entrelazan y se manifiestan de distinta manera en función del contexto sociocultural, por ejemplo: entre estudiantes (hombres y mujeres) de una universidad privada del noreste estadounidense prevalecía la creencia que en una cita, cuando el hombre pagaba la cena y en particular cuando era costosa, terminaría en una relación sexual, cuando no ocurría, se presentaba el riesgo de sufrir acoso sexual e incluso violación, a diferencia de cuando la cena no era costosa y era pagada por ambos en que tal creencia disminuía sensiblemente o no estaba presente (Basow y Minieri 2010). Tal como lo señala Villoro (1989), las creencias configuran la disposición del sujeto para llevar a cabo su práctica social.

\section{Notas SObRe El TRABAJO DE CAMPO}

El estudio del que forma parte este trabajo se orientó a identificar las creencias acerca de las normas y valores del "ser hombre" y "ser mujer"; las relaciones de pareja; las causas de la violencia que se ejerce contra las mujeres, sus consecuencias y justificación; los espacios de homosocialidad y heterosocialidad. Aquí se refiere a una creencia en particular: "traer cortita a la mujer". Las y los jóvenes la mencionaron en las primeras incursiones del trabajo de campo, por lo que se utilizó como una frase generadora en sesiones de grupos focales. Como se verá más delante, los comentarios sobre esta creencia evidencian la tensión en las relaciones de género, el sustrato sobre el que puede construirse y legitimarse la VG, que no necesariamente deviene en coerción física, pero sí en violencia simbólica.

El trabajo de campo transcurrió entre noviembre de 2006 y noviembre de 2007. En el año 2005 la población de 15-24 años de edad residente en la Zona Metropolitana de Guadalajara era de 766,082 , correspondía a $21.9 \%$ de la población total. Del total de jóvenes sólo 37\% asistía a la escuela (INEGi 2008). Quienes participaron en el estudio formaban parte de este sector poblacional.

El estudio incluyó a estudiantes de una universidad pública y de una universidad privada de las áreas administrativas, económicas, ingenierías y diseño. De la universidad pública se incluyeron a estu- 
diantes de un plantel de bachillerato. Se reclutaron jóvenes para la conformación de grupos focales. En total se realizaron 15 sesiones, subdivididas por grupo de edad (15-17; 18-20 y 21-24 años) y sexo (seis fueron mixtos, cinco con mujeres y cuatro con hombres). El reclutamiento fue por invitación: directa y abierta pasando a cada salón de clase, por medio de la sociedad de alumnos y por medio de una promotora de salud. Las sesiones se llevaron a cabo en espacios cerrados. Tuvieron una duración variable, el rango osciló entre una hora y un minuto a dos horas con dos minutos. En promedio, ocho jóvenes participaron en cada grupo focal. Cuatro en el de menor participación y 16 en el de más.

Previo al inicio de cada sesión se expusieron los objetivos del proyecto; los usos que se daría a la información; la importancia de la participación y su representatividad; las reglas que seguir en el grupo focal; y los criterios éticos de la investigación. Se solicitó autorización para grabar la sesión. Se transcribieron las sesiones utilizando el programa Dragon Natural Speaking Preferred v.9 y se procesó la información con la ayuda del programa Nud*Ist v.6.

Antes de iniciar el trabajo de campo se estableció un acuerdo con el programa "Gente Joven" de MEXFAM ${ }^{1}$ y con el Consejo Estatal para la Prevención y Atención de la Violencia Intrafamiliar del Estado de Jalisco, para que brindaran servicios a jóvenes que durante el proyecto requirieran apoyo. Durante el proceso solamente un hombre del grupo de 18 a 20 años solicitó información sobre adicciones, gestionada vía internet. Se distribuyó entre las y los participantes: a) un folleto informativo sobre las temáticas relacionadas con el proyecto y lugares donde se puede obtener apoyo; b) se utilizó un cuestionario (autoaplicado) anónimo para identificar las características sociodemográficas.

Participaron 124 jóvenes, $54 \%$ mujeres y $46 \%$ varones. $40.3 \%$ se encontraba cursando una licenciatura, mientras que $59.7 \%$ algún grado del nivel medio superior. Casi la totalidad eran solteros (99.2\%), sólo una mujer se encontraba separada de su pareja. Res-

${ }^{1}$ Fundación Mexicana para la Planeación Familiar (MEXFAM), institución privada de servicios de salud reproductiva y salud sexual. 
pecto del lugar de nacimiento, los municipios de Zapopan y Guadalajara registraron los niveles más altos $(29.0 \%$ y $27.4 \%$, respectivamente), le siguieron Tlaquepaque con $2.4 \%$ y en diversos municipios $8.1 \% .^{2}$ De los alumnos, $13.7 \%$ residía en Guadalajara, mientras que en Zapopan estaba la mayor proporción (50.8\%). 43.5\% desarrollaba una actividad laboral; $77.4 \%$ tenía automóvil propio en su hogar; $93.5 \%$ tenía teléfono particular; $99.2 \%$, refrigerador en su hogar; y 83.9\%, equipo de cómputo en casa.

\section{Jóvenes ANTE LA CREENCIA "TRAer CORTITA A LA MUJER"}

A continuación se presentan segmentos de las participantes en los grupos focales. La importancia de presentar el fragmento es hacer notar la formulación discursiva grupal. La construcción del discurso no es lineal, se generan contradicciones y tensiones, se construyen sinergias. Dichas formulaciones discursivas no son ajenas al espacio sociocultural del que forman parte los y las jóvenes, sino que las reproducen. Su reproducción no es necesariamente mecánica, hay posiciones reflexivas y críticas, otras reivindican posiciones conservadoras sobre las asimetrías entre los géneros. Con ello se quiere enfatizar la diversidad de perspectivas y, en tal sentido, las continuidades y transformaciones en las creencias sobre las relaciones de género.

En primer término se muestran las intervenciones en los grupos de mujeres.

\section{La voz de las jóvenes}

Entre las mujeres no existe un consenso sobre la creencia "traer cortitas a las mujeres". En términos generales hay tres posiciones más o menos diferenciadas. Una de ellas es la pertinencia de "traer cortita a la mujer" por parte del hombre, que sería un extremo. Otra cuando en lugar de "traer cortita a la mujer", la relación está marcada por la despreocupación por parte del hombre, parecería que él se

${ }^{2} 33.1 \%$ no contestó esta pregunta, debido a que se incluyó en el cuestionario una vez que el trabajo de campo se encontraba en proceso. 
mueve en la indiferencia hacia ella. Una tercera es aquella que busca un "equilibrio" en la relación. Veamos cada una de estas posiciones.

\section{(Grupo de mujeres de 21-24 años)}

Facilitador: Dicen que a las mujeres les gusta que las traigan cortitas [risas] Mujer 2: Si es masoquista yo creo que sí [sonríe].

Mujer 1: No, creo que no.

Facilitador: ¿Qué piensan de eso?

Mujer 4: ¿Cortitas en qué sentido, por ejemplo a que te estén presionando? Yo pienso que sí. De cierta manera sí. Por ejemplo, yo tenía un novio, si no me hablaba tres veces al día y no lo veía, si no me hablaba, yo sentía ¿por qué no me habla?, ¿qué estará haciendo? Como que quieres que te estén ... Mujer 5: Cuidando.

Mujer 4: Ajá, al pendiente. Como decir: si no te llama es que ya no te quieren o no se acuerda de ti.

"Mujer 4" asocia "traer cortita" con la presión que el hombre ejerce sobre la mujer. Lo ejemplifica con su experiencia personal. Mas no es propiamente el hecho de experimentar coacción, sino que lo entiende como una manera de permanencia en el pensamiento del hombre. El hecho de no recibir llamadas (en el celular) "¿por qué no me habla?" lo asocia a la carencia de afecto, de cuidado, o como ella misma lo expresa, de estar "al pendiente", atento a ella. Cabe cuestionarse sobre la idea de amor que subyace a esta creencia.

"Mujer 4" parecería no compartir la creencia de que "traer cortita” a la mujer es un ejemplo masoquista de relación como lo señala "Mujer 2", ni que sea una no deseable, sino que la relación basada en "traer cortita a la mujer", es deseable pero "de cierta manera" y eso es lo que expone. Su concepción de verse en una relación que es presionada por el varón, sí, pero "de cierta manera". No es una presión cualquiera, sino acotada para solventar lo que describe como una necesidad afectiva. Si bien se podría considerar esta última como una característica psicológica de "Mujer 4", más bien habría que preguntarse en cómo ha sido socializada, para concebir esa forma de relación social como una relación amorosa, deseable, una relación afectiva pertinente. 
La connotación de reprobación de esta forma de relación social "traer cortita" a la mujer está asociada también a una forma "machista" de práctica social vigente, pero con creciente pérdida de legitimidad, como lo menciona "Mujer 1".

(Grupo de mujeres de 21-24 años)

Mujer 1: Yo creo que esa idea de traerse cortita a las mujeres es más apegada al machismo que antes se aceptaba más. Que todavía existe pero ya no tiene tanta aceptación, o ya se exterioriza más, y como el dicho de antes: si no te pega no te quiere ¿̨no? Si no me cela pues no le intereso. Yo creo que todo en medida ¿¿no? Si me ve con otro y no me dice nada jah! pos entonces soy indiferente. Pero ni tanto que queme al santo, ni tanto que no lo alumbre [dicen a coro: ni tanto que no lo alumbre], o sea, tenerse el interés, pero a la vez el respeto de ambas partes.

Ni machismo, ni indiferencia, lo deseable de la relación es que sea respetuosa e interesada por la persona. Ya lo dice el dicho: "ni tanto que queme al santo, ni tanto que no lo alumbre”. Éste es un terreno movedizo, de fronteras que se construyen de manera permanente.

El reconocimiento de la existencia de machismo, expresión autoritaria de relación es una práctica inaceptable para cierto grupo de mujeres como la creencia "si no me pega, no me quiere" o mostrarse celoso que significa interés. Al parecer entre las mujeres más jóvenes en este estudio, la sujeción de la mujer al hombre no tiene ningún eco. Lo que para "Mujer 4" es deseable, para otras jóvenes, es abrumador. Es motivo de hartazgo que propicia el rompimiento de la relación.

"Llamar" (al teléfono celular) tiene sus límites, tanto en cantidad como en la forma de contenido de la llamada. Todas estas variantes son importantes de considerar porque no existe un patrón preestablecido.

(Grupo de mujeres de 15-17 años)

Facilitador: Dicen por ahí que a las mujeres hay que traerlas bien cortitas. Mujer 6: No. Dicen pero no es cierto.

Mujer 7. Es lo contrario porque si te traen más cortita te hartas más y es así como que...

Mujer 8: Hasta eres más mala, la verdad, mala nińa. 
Mujer 6: Hay ciertas mujeres [bajando la voz hasta que no se escucha lo que sigue diciendo].

Mujer 7: Bueno igual y yo insisto con mi equilibrio. Es que [sonríe] siento que también tanta libertad, por ejemplo: que jamás te llamen [dicen a coro: no], también lo tomas como: ¡chin! que ni se preocupa.

Mujer 8: No le importas.

Mujer 10: Así como que ni se acuerda de que tiene novia.

Mujer 7: Tiene que haber un equilibrio. De vez en cuando llamar, pero también en exceso pues ya [le arrebatan la palabra].

Mujer 8: Tampoco ser aferrado a eso, pero sí.

Mujer 6: No es lo mismo a que te llamen y que te digan: Hola ¿̨ónde estás?, a que ¡¿dónde estás?! ¡¿Con quién?! ¡¡Por qué?! Nosotras tenemos que ahí marcar la diferencia y poner nuestros límites y nuestras reglas.

Una cosa es recibir llamadas en que se cuestiona, se fiscaliza el proceder de la mujer, y otra muy diferente es la llamada informativa y casual, que muestra interés por la persona. Los recursos electrónicos son un instrumento con múltiples usos.

Destaca la mención de estas jóvenes sobre la negociación de la relación. El vínculo afectivo está sujeto a transacción, no es algo que se debe dejar fluir y seguir una ruta impredecible, azarosa, sino que se construye en función de intereses que se negocian.

La frontera en la relación, fincada en el establecimiento de límites, de reglas que se deben expresar dejan de lado supuestos, sobreentendidos, o como dice "Mujer 6": "poner nuestros límites y nuestras reglas". No es que éstos pasen a un segundo término, los supuestos no tienen cabida. La relación al parecer debe fincarse en el señalamiento explícito de lo que se espera de cada quien. Es la conformación de un contrato amoroso, basado en lo que podría considerarse como principios: la confianza y el respeto.

(Grupo de mujeres de 18-20 años)

Facilitador: Dicen que a las mujeres hay que traerlas cortitas [risas]. Ustedes, ¿qué piensan de eso?

Mujer 11: Yo digo que no. Cada quien necesita su espacio. Si uno tiene la suficiente confianza en la otra persona no se ocupa tener cortito a alguien. 
Si tienes confianza dices: yo estoy consciente de que tiene que hacer sus cosas, que quiere ir a convivir con sus amigos. Pero también él está consciente que lo quiero y, por lo tanto, va a respetar la relación.

Mujer 12: Que se tenga confianza y mucha comunicación entre ellos. Que tú como mujer le expongas: ¿̇sabes qué? Yo quiero salir con mis amigas por esto, y por lo otro. Que se tenga mucha comunicación y confianza para decirse las cosas. No es necesario que te traigan cortito, porque tú sabes qué va a hacer él, y él sabe qué vas a hacer tú. Y se supone que tú le estas fomentando confianza en ti. Entonces no tienes porque [le arrebatan la palabra].

Mujer 13: Aunque no sepa qué vas a hacer, él confía en ti.

No se deja nada a la imaginación. Se comunica, se dialoga, se acuerda. Se parte de la confianza, respeto, reciprocidad e igualdad, que como menciono son principios sobre los que estas jóvenes desean establecer vínculos. "Traer cortita a la mujer" supone posiciones asimétricas en la relación, quien controla y quien se sujeta a ese control. ¿Cómo es que estas mujeres jóvenes se asumen en igualdad ante los hombres? ¿Qué es lo que ha posibilitado la desestructuración de ver al otro como superior? ¿Es la familia, los medios de comunicación, el grupo de pares, la escuela, las experiencias personales?

Contraponer el control a la igualdad implica necesariamente un cambio en las premisas relacionales. Mientras que la primera supone un orden social jerárquico, segmentación de actividades y asignación de potencialidades humanas según género, por tanto una asignación valorativa que tiene un doble estándar, uno para las mujeres, otro para los hombres, la segunda establece una base que identifica a hombres y mujeres en el mismo plano, sin privilegios, la valoración del individuo está sostenida por el respeto, en el reconocimiento del otro, los mismos derechos y obligaciones. Ante un igual no cabe la imposición, sino la exposición, se saben diferentes pero en igualdad, "le expongas: 'sabes que yo quiero salir con mis amigas por esto, y por lo otro', y no sé, o sea, que se tenga mucha comunicación y confianza para decirse las cosas".

Es una relación de confianza. No se puede confiar en alguien a quien no respetas. A quien no reconoces en igualdad de circunstan- 
cias. Si se suponen iguales, la única vía aceptable de relación es a través del diálogo y el acuerdo que sustituyen a la imposición y el sometimiento, "traer cortita a la mujer".

Otro aspecto relevante de este reposicionamiento de estas jóvenes es declararse como individuos independientes y no un complemento de los hombres. Individuos con necesidades específicas como cualquier otro. Las relaciones sociales no se limitan a la pareja, al novio, sino que se tiene una red social a la que no está dispuesta a renunciar, más bien le interesa mantenerla y quizá compartirla, pero no autoexcluirse. Parecería entonces que se busca un enriquecimiento en lugar de una sustitución. La red de amistades no es sustitución del novio. Cada uno viene a llenar una necesidad diferenciada. Además existen ocupaciones que debe atender cada quien, sin menoscabo de la propia relación afectiva: "estoy consciente de que tiene que hacer sus cosas, o que quiere ir a convivir con sus amigos, o algo. Pero, también, está consciente ella en que, o él, que lo quiero y que esto y que lo otro. Y que por lo tanto, va a respetar la relación”.

Entre estas jóvenes no existe un consenso sobre la creencia "traer cortita a la mujer”. Cuando se justifica se antepone una motivación afectiva y se explicita su modalidad del "traer cortita", aunque para otras eso suene a "masoquismo". Otras la identifican como una expresión de machismo, al igual que otras creencias: "si no me pega no me quiere", "si no me cela..." modalidades de violencia física y psicológica. La tercera modalidad es la formulación de un contra discurso basado en la exposición y la negociación. Un elemento común es el uso de la tecnología sobre el que llamaré la atención más delante.

\section{La voz de los jóvenes}

Los varones jóvenes tienen una perspectiva más acotada sobre las implicaciones de "traer cortita a la mujer". Por una parte se identifica como: a) expresión de machismo, una forma no deseable de relación; b) como un mandato que se actualiza en la familia y el noviazgo; c) como una lucha de poder; y d) como una forma atractiva y deseada por las mismas mujeres. Veamos cada una de ellas. 
(Grupo "A" de hombres de 15-17 años)

Facilitador: Hay muchas personas que dicen que a las chavas hay que traerlas bien cortitas.

Hombre 4: ;Ay no!

Hombre 3: Bien cortitas.

Hombre 1: Son celosos

Hombre 4: Son enfermos.

Hombre 5: Eso ya es un machismo. Son poco hombres, son bien mensos, porque eso no se debe. Cada quien tiene libertad de tener, por ejemplo, los novios, si se quieren, cada uno va a respetar su noviazgo, sentir confianza. Hombre 6: Yo digo que el que dice eso, es porque no tiene confianza en ella ni en sí mismo.

Hombre 2: Él la engaña y no quiere que se la apliquen.

Hombre 5: Por ejemplo los novios, que le habla a su novia que dónde está, qué está haciendo, nomás está checando. Que no mame; está en la escuela, qué debe hacer, pues está estudiando, cotorreando. Hay muchos novios que se van de fiesta a escondidas y nomás se les enoja la mujer jah! Se quejan ¿eda? Y se va su novia a una fiesta, entonces el hombre siempre le está reclamando, se queja. Siempre pueden hacer todo los hombres y las mujeres nada, eso es algo mamón.

Algunos consideran que esa forma de relación es una manifestación de machismo, es una práctica reprobable. Incluso es una evidencia de una masculinidad incompleta o dudosa "poco hombre". Ser macho aparece como un padecimiento (son enfermos), es una manera de criticar una masculinidad basada en el control, la vigilancia sobre ellas con el mismo recurso tecnológico mencionado por las mujeres. Otro componente es la doble moral (tener más de una pareja) de algunos hombres, por lo que su temor es ser objeto de una práctica similar. La desconfianza en la mujer es una proyección de una experiencia personal. Hay motivaciones, una racionalidad y una experiencia que dispone a la actualización de una creencia.

(Grupo "B" de hombres de 15 a 17 años)

Facilitador: Hay algunas personas que dicen que a las chavas hay que traerlas muy cortitas porque si no se les salen del huacal, ¿ustedes qué piensan de eso? 
Hombre 7: Pues a mí en lo personal tengo una hermana que es más grande que yo, cuando va a salir o algo que pide permiso. Yo la llevo a donde va ir y yo la recojo. Mi papá es lo que me encarga: que la meta temprano. Si va a salir conmigo a una fiesta, a ella la tengo que dejar a cierta hora y ya si quiero me regreso, si no, ya me quedo también ahí. Estarla cuidando. Tengo otra más chiquita que no sale todavía.

Facilitador: Pero la más grande tú la cuidas. ¿Y ustedes qué piensan de eso? ¿Qué piensan de que a las novias hay que traerlas aquí [apretando el puño izquierdo]? Porque si no... [le arrebatan la palabra].

Hombre 8: Eso sí. A las novias sí.

Facilitador: ¿A las novias sí? ¿Qué es lo que pasa si no traes cortitas a las novias?

Hombre 8: Si le das mucha libertad pues va a empezar a hacer lo que le da su gana, incluso hasta el no respetar el estar contigo, por ejemplo, si tenían un acuerdo de que, no pues vamos a estar juntos de tal hora a tal hora, "no pues sabes que me voy a ir con mis cuates" y ya empieza a valer madre. Se acaba todo, empieza en puras saliditas. Y ya después hasta el cuerno le ponen a uno.

En este fragmento se exponen dos acepciones de "traer cortita a la mujer". Una como parte de las relaciones familiares y otra en las relaciones afectivas de pareja, en el noviazgo. En la primera, tutelar a la mujer es una "responsabilidad" del hombre. No parece importar diferencias de edad, el hombre tiene por mandato "cuidar" a la mujer. En este caso, "Hombre 7" es responsabilizado por su padre del cuidado de su hermana mayor. Una u otro tienen grados diferentes de sujeción a la autoridad paterna, de libertad, de autonomía. La edad no es un elemento a partir del cual se establece un criterio de cuidado y autonomía, al menos en este caso no es la edad, es el género. La masculinidad es investida de autoridad y de responsabilidad ante una feminidad que se vive bajo la supervisión de los varones: el padre, el hermano menor.

Hay al menos dos posibilidades de interpretación: que las mujeres "son seres desvalidos" que necesitan de un hombre que las defienda y proteja de otro hombre; otra posibilidad es que las mujeres son propensas a cometer excesos y, por tanto, necesitan mantenerse 
bajo la supervisión de la mirada masculina. En este caso particular, "traer cortita a la mujer" parece entenderse de una manera más amplia, se extiende a las mujeres de la familia.

Socialmente los hombres son investidos de poder. La investidura se actualiza dentro de las instituciones como práctica cotidiana, en este caso en la familia, en las relaciones entre sus integrantes que reproducen y matizan las expresiones de ejercicio de poder entre los géneros (Kaufman 1997).

La segunda acepción de "traer cortita a la mujer", la ofrece "Hombre 8", como un mandato de género, una creencia, no es tan amplio, sino más bien debe de sufrir una acotación: "A las novias sí". Aquellas que han establecido un vínculo de formalidad en el proceso de cortejo, deben estar supeditadas al varón. La tutela aparece como una característica de la masculinidad que se ejerce regulando a la mujer. Las mujeres deben de gozar de libertad, pero no mucha. Parecería que las mujeres tienen particular propensión a corromperse, a abusar, por lo que es necesaria la supervisión. Mantenerse alerta para evitarle cualquier desvío. Que puede terminar en el engaño, "hasta el cuerno le ponen a uno", quedando en entredicho la masculinidad del sujeto.

Otros jóvenes ven en la creencia de "traerla cortita" una clara evidencia de maltrato por parte de los hombres hacia las mujeres. Las razones que aducen son: el gusto de las mujeres por esa forma de relación, por el maltrato; la necesidad de recurrir al maltrato a pesar de que ellos puedan desear tratar bien a la mujer, debido a que puede darse abuso por parte de ellas, sacar ventaja en la relación. También se aduce que el maltrato genera inseguridad en la relación por parte de la mujer, y esa incertidumbre favorece que en la mujer se incremente la búsqueda de afianzar la relación, ya que no se ha logrado obtener todo el afecto del hombre.

Grupo de hombres de 18-20 años

Facilitador: Decían que hay que traerla cortita.

Hombre 9: Bien cortita [risas].

Facilitador: Ustedes, ¿qué piensan de eso? De que a las mujeres [le arrebatan la palabra]. 
Hombre 10: A algunas mujeres les gusta que las traten mal. Sí es cierto. Hombre 11: A todas les gusta las traten mal. Sinceramente, les gusta la mala vida [le arrebatan la palabra].

Hombre 10: Que uno las trata bien [le arrebatan la palabra].

Hombre 9: Y te traen de su pendejo [sonríe], la neta [le arrebatan la palabra]. Hombre 9: Como decía mi padre, ¿¿no? A las mujeres ni todo el amor ni todo el dinero.

Hombre 11. Sí, es que les gusta que las traten mal. Yo ya lo tengo comprobado [risas] por qué, por ejemplo, si las tratas bien, se encajan. Y si las tratas mal, si son listas, dicen: no, hasta aquí y mejor se alejan. Se alejan uno del otro. Pero, comúnmente, cuando las tratas mal es cuando más ahí están [le arrebatan la palabra] [truena los dedos].

Hombre 10: Y las traes aquí [Empuña la mano y le arrebatan la palabra]. Hombre 9: Si las tratas bien, te agarran de su pendejo. Si las tratas mal, eres un culero [le arrebatan la palabra].

Hombre 12: Y es que es lo difícil, porque cuando, cuando a uno le gusta una persona tú lo que quieres es tratarla bien. Pero después dices: "no, si la trató bien... pues deja le doy unas [Hombre 11: cachetaditas] unos desaires para que, sí no es que lo quiera hacer a propósito, sino que dices: "es que ella va a ver que no la quiero tanto y...”

Presentan la relación como una imposibilidad de conciliación de intereses, de diálogo, como una lucha de poder en que no es posible la equidad. No existe negociación, sino imposición, ya sea de ella sobre él o viceversa. Las mujeres son vistas con recelo, como un oponente al que hay que someter o correr el riesgo de ser sometido. En lugar de confianza, es el cálculo del avance de la posición hacia el control de la relación, lo que lleva al varón a mantenerse vigilante, no perder detalle y dar la valoración correcta. La relación adquiere una connotación de cálculo, parecería que lejos está el disfrute y el gozo de la compañía, sino que se presenta como un mal necesario (Ramírez Rodríguez 2005).

(Grupo de hombres de 18-20 años)

Hombre 9: Si puede haber equidad, pero yo creo que hasta cierto punto ¿no? Pero no siempre. Uno siempre va a dar más que el otro. 
Facilitador: $\mathrm{Y}$, ¿cuál es ese punto?

Hombre 12: Cuando uno ve que ya se encajó [le arrebatan la palabra].

Hombre 11: Es que debes traerla, cortita. Mi abuelo decía: a la mujer hay que traerla en los pies.

La forma de representarse a la mujer como un agente que amenaza la seguridad y bienestar del hombre, tal cual lo muestra "Hombre 11 " no es una novedad, es una versión actualizada de lo que mencionaban ancianos en estudios sobre relaciones de poder y relaciones de violencia en la pareja. Llama la atención la persistencia de dichas creencias. ¿Por qué persisten estas creencias? ¿Cómo se mantienen vigentes? ¿En quiénes si y en quiénes no?

La persistencia de las creencias se relaciona con su capacidad adaptativa (Sabada 1978). Así, esta creencia de que las mujeres buscan el control sobre el hombre, aludida explícitamente por individuos en el primer tercio del siglo $\mathrm{xx},{ }^{3}$ vuelve a replantearse por jóvenes a inicios del siglo XxI. Una creencia que es cuestionada por muchas jóvenes y también por ciertos hombres jóvenes, que es exhibida como inoperante, caduca, una reminiscencia de tiempos idos, es reestructurada, puesta al día y presentada con elementos racionales, motivacionales y experiencias que legitiman el ejercicio de poder, la dominación masculina.

\section{Consideraciones finales}

Para finalizar, enfatizo algunos cuestionamientos y aspectos particulares de las creencias que pueden estar contribuyendo a mantenerlas vigentes. Después discuto ciertos hallazgos presentados en la sección

${ }^{3}$ David (79 años): "Pues mire esa cosa depende de la actitud de la mujer. Por ejemplo, empieza la mujer a contestarle a uno por algo por simplemente una sencilla cosa de que usted le manda oye tráeme aquello. No pos tráelo tú. Ai nada más estás sentado. Entonces allí si el hombre no le promedia aquello, la mujer sube. Porque está el dicho que dice que la mujer brinca tres veces. Como decía la agüelita, le decía a la hija. Dijo mi agüelita que a las tres veces me subía hasta los hombros y ya no podía bajar. Entonces le dice al hombre, no pos dice, me dijo mi agüelita, yo tenía agüelita y me dijo que las mujeres brincaban tres veces, pero ahora una vas a brincar tú" (Ramírez Rodríguez 2005). 
previa y termino con una serie de anotaciones sobre ámbitos temáticos relevantes para continuar analizando el vínculo creencias-género-jóvenes.

¿Por qué persiste la creencia de traer cortita a la mujer? ¿Cómo se mantiene vigente? ¿En quiénes tiene eco y en quiénes no? ¿En qué está fundamentada cierta propensión para adoptar esta creencia o rechazarla? Sabada ofrece algunas ideas para adelantar una reflexión sobre estas preguntas. Afirma que un elemento de la creencia es su capacidad adaptativa. "Conquista todo; su imperialismo es admirable. Su fragilidad ósea le posibilita reestructurarse a gran velocidad" (Sabada 1978, 21). Esta característica de la creencia descansa en los distintos elementos que la conforman: la experiencia, el motivo y la razón. La experiencia refiere un momento histórico, biográfico, la circunstancia en que el sujeto vive un hecho particular en que está presente de manera explícita la creencia y su contenido, adoptándola como propia; el motivo alude a la función que tiene la creencia para la realización de los deseos, necesidades e intenciones del sujeto; por último, las razones, la justificación de la creencia (Villoro 1989). Parecería que modificar la creencia implica por necesidad una adecuación del conjunto de elementos. No basta la información, se requiere tener motivos y, también, alguna experiencia que sirva como referente. Además, la creencia no es un estanco, sino que está entrelazada con otras creencias afines, constituyéndose en sistemas más o menos armónicos, que le dotan a un individuo de recursos para sortear, casi siempre de manera exitosa, cualquier posible cuestionamiento, contraposición y exposición a otras creencias. En todo caso, las creencias son un terreno en conflicto, algunas veces silenciado, otras tantas como un jaleo soterrado, unas más como un campo explícito en amplio y frontal debate, tal es el caso de las relaciones de género, como se ha podido constatar.

Los términos que surgieron al referir la creencia "traer cortita a la mujer" fueron los siguientes: amor, dinero, buen y mal trato, equidad, aprovecharse, confianza, respeto, comunicación, machismo, prohibir, celos, inseguridad, reciprocidad, madurez, cuidado, libertad, atención, responsabilidad, diferencias, interés, acoso, hartazgo, enfermedad, engaño, educación, reclamo, acuerdo, equilibrio, límites, 
poder, autoridad, parejo, presionar, hostigar, enfadar, mandar. Esta creencia no pasa inadvertida, por el contrario, genera reacciones muy diversas, posiciones a favor y en contra. Consideraciones críticas y reflexiones sobre su pertinencia; evidencia elementos del contexto sociocultural, permanencias y cambios generacionales. Esta creencia, sin lugar a duda, ha sido útil para discutir las tensiones que se generan en las relaciones de género en la población de jóvenes.

No hay lugar a confusión, "traer cortita a la mujer" es una forma de control de un hombre sobre una mujer. La subordinación puede aceptarse o no, considerarse adecuada o no, ("en las novias sî"; "eso es lo de que decíamos antes de machismo"), incluso se puede mirar como un gradiente "hasta cierto punto". No hay consenso sino variantes sobre la pertinencia de esta creencia. Las jóvenes se muestran más claramente en oposición a esta creencia a diferencia de los hombres, más proclives a mantenerla. Ellas la consideran una forma de machismo, ante lo que elaboran un contra discurso. Ante la creencia que reproduce la dominación, plantean la necesidad de relaciones más "equitativas" basadas en el diálogo, la negociación, la exposición de argumentos, la relación entre iguales capaces de llegar a acuerdos sostenidos en la confianza. Cuando se asiente sobre "traer cortita a la mujer" se acota, se precisa en qué sentido, cómo entenderla y se insiste en el establecimiento de reglas, de límites en la relación. En otras palabras se condiciona, no es una aceptación incondicional.

Los hombres jóvenes muestran una serie de argumentos que refuerzan la creencia de dominación sobre las mujeres. La influencia de la familia es muy importante. Existe en algunos casos una clara complicidad intergeneracional que se manifiesta como mandato de género, de una masculinidad que se actualiza en la vigilancia de las mujeres, encubierta en el eufemismo del cuidado, de la protección de la mujer por parte del hombre. Se refuerza así una noción de incapacidad de la mujer para ejercer la autonomía, el cuidado de sí misma y desde luego la imposibilidad de que proteja o cuide al hombre. Se protege y cuida a la persona desvalida. La creencia "traer cortita a la mujer" puede y de hecho se extiende también al ámbito familiar, aunque no es una noción generalizable. 
"Traer cortita a la mujer" implica vigilancia de ellas por parte de los hombres. El descuido puede colocar a los hombres, a los novios, como "cornudos", incompetentes para mantener el control sobre la pareja. El contra discurso de relaciones de igualdad y equidad elaborado por las mujeres enfrenta una contraparte que insiste en la imposibilidad de alcanzar la equidad. Ésta puede ser incluso deseada por los hombres, hay una motivación, pero la experiencia reconstituye la creencia y cierra la posibilidad de cambio. Se mantiene la relación entre los géneros como una relación de poder encajonada en la búsqueda constante de la subordinación, en el maltrato que incluso se menciona como deseado por ellas.

También hay jóvenes que no comparten la creencia "traer cortita a la mujer”, más bien la reprueban. Al parecer son una minoría, no obstante es muy significativa. Sus motivaciones, argumentos y experiencias pueden ser útiles para construir relaciones de igualdad. Asimismo, desafían una subjetividad anclada en la dominación masculina, en la violencia simbólica.

En este juego de relaciones en torno a la creencia de "traer cortita a la mujer" parecería que la comunicación electrónica (las llamadas telefónicas y los mensajes) tiene un papel importante. Es un instrumento poco analizado; sin lugar a duda es un recurso con múltiples usos. Uno de ellos es el ejercicio de la dominación masculina. A la vez se reconoce su utilidad para mantener relaciones armoniosas y carińosas. Las redes e instrumentos de comunicación que establecen las y los jóvenes son un campo que requiere mayor atención. Profundizar en ello permitiría comprender la manera en que los recursos tecnológicos están siendo utilizados en la reconfiguración de las creencias en las relaciones de género y las relaciones de violencia.

Queda evidenciada la manera en que mujeres y hombres cuestionan la creencia. Las más jóvenes son quienes identifican una serie de "normas" para evitar caer en el uso de recursos coercitivos que se desprenden de "traer cortita a la mujer". ¿Cómo es que estas mujeres jóvenes se asumen en igualdad ante los hombres? ¿Qué es lo que ha posibilitado la desestructuración de ver al otro como superior? ¿Es la familia, los medios de comunicación, el grupo de pares, la escuela, las experiencias personales? Desde mi punto de vista, éstas son pre- 
guntas relevantes porque su respuesta apuntaría a construir estrategias de transformación para establecer formas de relación más igualitarias, fundamentadas en el diálogo, el respeto, la confianza, la solidaridad. Algunas jóvenes refieren la influencia de "las películas", otras de "mi mamá", otras contrastan su vida independiente, la autonomía que han ido construyendo con las experiencias de sus pares, que están dentro de la misma familia o con su círculo de amistades. Parecería que mientras más opciones conocen, tienen un panorama mayor de posibles relaciones y, por tanto, se pueden cuestionar sobre por cuál optar y con qué fundamento.

Entre los hombres también se sostiene la importancia de formas no tradicionales de relación entre los géneros, como es el "traer cortita a la mujer”. Éste es otro filón por explorar, ¿por qué y cómo estos varones han encontrado vías alternas a la masculinidad dominante?, ¿quiénes han favorecido estos procesos?, ¿cómo se podrían potenciar estas avenidas que ya están transitando estos hombres jóvenes?

Otros elementos relevantes en la configuración de las creencias y que conviene tener presentes son: el vínculo entre creencias y las emociones (Elster 2001), que es un campo prácticamente desierto en el análisis de las relaciones de género y las relaciones de violencia entre la población juvenil. Considero que en la medida que se avance en la comprensión de este puente emoción-creencia-género, en particular la masculinidad, se podrá adelantar más rápidamente en la identificación de caminos de transformación. Caminos tendientes a fortalecer formas de expresión emocional flexibles basadas en lo que algunas mujeres y ciertos hombres demandan explícitamente: respeto, diálogo, acuerdo, igualdad. Por otra parte, reconocer las referencias explícitas que algunas de las y los jóvenes hacen al vínculo entre sentirse amados, cuidados, queridos, deseados, con la creencia de "traer cortita a la mujer", que en ocasiones se aduce como justificación de la vG.

\section{BiBLIOGRAFÍA}

ArIspe, Lourdes, Cultura y desarrollo. Una etnografia de las creencias de una comunidad mexicana, Las Ciencias Sociales, México, unam, El Colegio de México, Miguel Angel Porrúa, 1989. 
Basow, Susan A. y Alexandra Minieri, “'You Owe Me': Effects of Date Cost, Who Pays, Participant Gender, and Rape Myth Beliefs on Perceptions of Rape", J Interpers Violence, mayo 1-19, 2010.

Bourdieu, Pierre, El sentido práctico, Madrid, Taurus Humanidades, 1991.

, La dominación masculina, Colección Argumentos 238, Barcelona, Anagrama, 2000.

Bourdieu, Pierre y Loïc Wacquant, Respuestas. Por una Antropologia Reflexiva, México, Grijalbo, 1995.

Camara de Diputados del Honorable Congreso de la Unión, "Ley General de Acceso de las Mujeres a una Vida Libre de Violencia", Diario Oficial de la Federación, 2009.

Connell, R. W., Masculinities, Berkeley y Los Ángeles, University of California Press, 1995.

ELSTER, Jon, Sobre las pasiones: emoción, adicción y conducta humana, Barcelona, Editorial Paidós, 2001.

FosheE, Vangie A., "Gender Differences in Adolecent Dating Abuse Prevalence, Types and Injuries", Health Education Research 11, núm. 3, 1996, 275-286.

Foshee, Vangie A., Karl E. Bauman, Susan T. Ennett, Fletcher Linder, Thad Benefield y Chirayath Suchindran, "Assessing the Long-Term Effects of the Safe Dates Program and Booster in Preventing and Reducing Adolescent Dating Violence Victimization and Perpetration", American Journal of Public Health 94, núm. 4, 2004, 619-624.

GooD, Byron, Medicina, racionalidad y experiencia : una perspectiva antropológica, Barcelona, Ediciones Bellaterra, 2003.

INEGI, "Conteo de Población y Vivienda 2005 (en linea)", Instituto Nacional de Estadística, Geografía e Informática, <http://www. inegi.gob.mx/est/contenidos/espanol/proyectos/conteos/conteo2005/bd/consulta2005/pf12Mas.asp?s=est\&c=10403>.

, Encuesta Nacional sobre la Dinámica de las Relaciones en los Hogares 2003. Endireh. Estados Unidos Mexicanos, Aguascalientes, Instituto Nacional de Estadística, Geografía e Informática, 2004. 
, Encuesta Nacional sobre la Dinámica de las Relaciones en los Hogares 2006. Endireh. Tabulados Básicos. Estados Unidos Mexicanos, Aguascalientes, Instituto Nacional de Estadística, Geografía e Informática, 2008.

Instituto Mexicano DE la Juventud, "Encuesta Nacional de Violencia en las Relaciones de Noviazgo 2007”, 22, México, Instituto Mexicano de la Juventud, Secretaría de Educación Pública, 2008. Instituto Nacional de Salud Pública, Encuesta de Saludy Derechos de las Mujeres Indígenas, Cuernavaca, Instituto Nacional de Salud Pública, 2008.

Kaufman, Michael, "Las experiencias contradictorias del poder entre los hombres", en Teresa Valdés y José Olavarría, eds., Masculinidad/Es, 63-81, Santiago de Chile, Isis Internacional, Flacso-Chile, 1997.

Moore, Ann, "Gender Role Beliefs at Sexual Debut: Qualitative Evidence from Two Brazilian Cities", International Family Plannig Perspectives 32, núm. 1, 2006, 45-51.

NACIONES UnIDAS, Estudio a fondo sobre todas las formas de violencia contra la mujer (Informe del Secretario General), Nueva York, Naciones Unidas, Asamblea General, 2006.

, Violencia contra la mujer en la familia, Nueva York, Naciones Unidas, 1989.

Olais, Gustavo, Aurora Del Río y Martha Híjar, eds., Violencia contra las mujeres. Un reto para la Salud Pública en México. Informe Ejecutivo de la Encuesta Nacional de Violencia contra las Mujeres, México, Instituto Nacional de Salud Pública, Secretaría de Salud, 2004.

OMs, Informe mundial sobre la violencia y la salud, Publicación Científica y Técnica núm. 588. Washington, Organización Panamericana de la Salud, 2003.

Ortega y Gasset, José, Ideas y creencias, Séptima edición, Madrid, Espasa-Calpe, 1968 [1940].

RAmírez Rodríguez, Juan Carlos, "La violencia de varones contra sus parejas heterosexuales: realidades y desafíos. Un recuento de la producción mexicana", Salud Pública de México 48, núm. supl. 2, 2006, 315-327. 
, Madejas entreveradas: violencia, masculinidad y poder. Varones que ejercen violencia contra sus parejas, México, Plaza y Valdes, Universidad de Guadalajara, 2005.

, ¿Por qué quieres matarme poco a poco? La violencia contra la mujer, México, Fundación Mexicana para la Salud, 1999.

Ramírez Rodríguez, Juan Carlos, Gemma Cithlalli López López y Francisco José Padilla González, "¿Nuevas generaciones, nuevas creencias? Violencia de género y jóvenes”, Revista de Estudios de Género "La Ventana", núm. 29, 2009, 110-145.

Ramírez Rodríguez, Juan Carlos y Griselda Uribe VÁzQuez, "Mujer y violencia: un hecho cotidiano", Salud Pública de México 35, núm. 2, 1993, 148-160.

Ramírez Rodríguez, Juan Carlos y Patricia Noemí Vargas BeceRRA, "La Cifra 'Negra' de la violencia doméstica contra la mujer", en Los silencios de la salud reproductiva: violencia, sexualidad $y$ derechos reproductivos, editado por Asociación Mexicana de Población, México, Asociación Mexicana de Población (AMEP), Fundación John D. y Catherine T. MacArthur, 1998, 107-133. Red Nacional de Observatorios de Violencia Social y de GéNERO, "Red Nacional de Observatorios de Violencia Social y de Género", INDESOL, SEDESOL, http://violencia.redobservatorios. org/index.html.

SABADA, Javier, Qué es un sistema de creencias, Madrid, Mañana, DL, 1978.

Sсотт, Joan W., "El género: una categoría útil para el análisis histórico", en Marta Lamas, comp., El género: la construcción cultural de la diferencia sexual, México, Miguel Ángel Porrúa, 1997, 265-302.

Steinmetz, S. y M. M. Haj-Yahia, "Definitions of and Beliefs About Wife Abuse among Ultra-Orthodox Jewish Men from Israel", Journal of Interpersonal Violence 21, núm. 4, 2006, 525-554. VALDEZ, Rosario y Clara JuÁREZ, "Impacto de la violencia doméstica en la salud mental de las mujeres: análisis y perspectivas en México", Salud Mental 21, núm. 6, 1998, 1-10.

Valdez Santiago, Rosario, "Del silencio privado a las agendas públicas. El devenir de la lucha contra la violencia doméstica en 
México", en Martha Torres, ed., Violencia contra las mujeres en contextos urbanos y rurales, México, El Colegio de México, 2004, 417-447.

Valdez Santiago, Rosario, Luz Arenas Monreal e Isabel HerNÁNDEZ TEZOQuipa, "Experiencia de las parteras en la identificación de mujeres maltratadas durante el embarazo", Salud Pública de México 46, núm. 1, 2004, 56-63.

VIlloro, Luis, Creer, saber, conocer, México, Siglo XXI Editores, 1989.

Welzer-Lang, Daniel, La violencia doméstica a través de 60 preguntas y 59 respuestas, Madrid, Alianza Editorial, 2007.

FECha DE RECEPCIÓN DEL ARTÍCULO: 12 de noviembre de 2010 FECHA DE RECEPCIÓN DE LA VERSIÓN FINAL: 5 de abril de 2011 